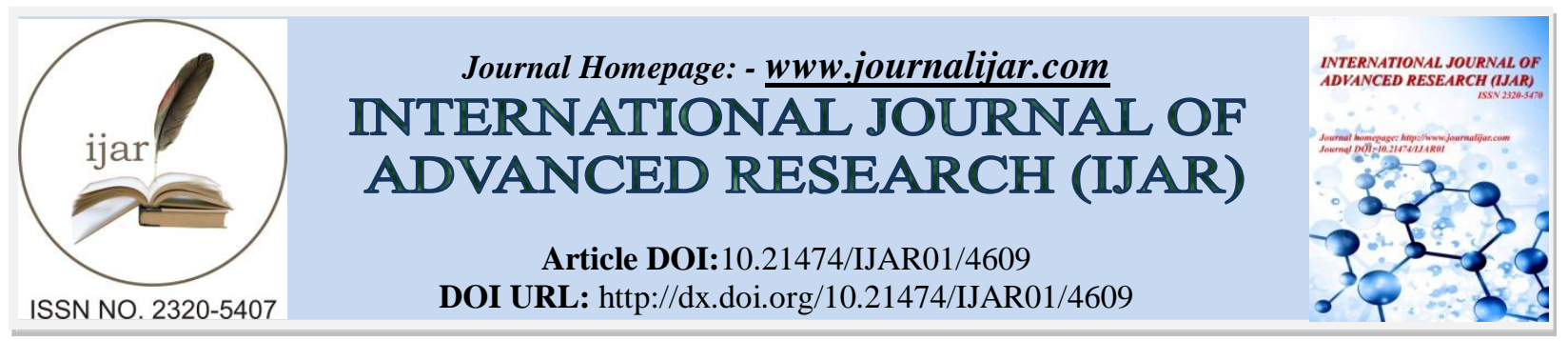

RESEARCH ARTICLE

\title{
A DESCRIPTIVE STUDY OF IMPACT OF MOBILE MARKETING ON CONSUMER BEHAVIOR IN INDIA.
}

Mrs. AnjalliVachhani

Assistant Professor (Department of Accountancy) H.R. College of Commerce and Economics, University of Mumbai.

\section{Manuscript Info}

(1.........................

\section{Manuscript History}

Received: 25 April 2017

Final Accepted: 27 May 2017

Published: June 2017

Key words:-

Mobile Marketing, Consumer behavior, Impact

\section{Abstract}

Mobile marketing is the cooperating multichannel promotion of products or services for mobile phones and devices, smartphones and networks. Mobile marketing is marketing on a mobile device, such as a smart phone. Mobile marketing offer consumers with time and location elusive, custom-made information that promotes goods, services and ideas. Some mobile marketing is parallel to advertising delivered over other electronic channels such as text, graphic and voice messages. SMS messaging is presently the most common delivery channel for mobile marketing. Search engine marketing is the second-most common channel, shadowed by display-based campaigns. This qualitative research attempts to describe the concept of Mobile Marketing and to evaluate the impact of Mobile marketing on consumers' behavior in India.

Copy Right, IJAR, 2017,. All rights reserved.

\section{Introduction:-}

Mobile marketing is marketing that takes place via mobile devices such as smart phones, tablets or PDAs. Mobile marketing makes practice of structures of current mobile technology such as location services to adapt marketing campaigns based on a customer's location or regularly visited places. Mobile marketing is a system in which technology can encourage personalized goods or services to a operator who is regularly linked to a network via their mobile device.

Mobile marketing may comprise of promotions sent through SMS text messaging, MMS multimedia messaging, through downloaded apps using push notifications, through in-app or in-game marketing, through portable web sites, or by using a portable device to scan QR codes. Proximity systems and location based services can aware users based on geographic place or proximity to a service provider. Mobile marketing is parallel to electronic advertising and uses text, graphics and voice messages.

As per Morgan Stanley Research, number of mobile device operators universally has augmented from 1100 million in 2007 to 1700 million users in 2015. In India, E-Marketer approximates that mobile is a minor but emergent element of digital advertising. The earlier prediction for total media, digital and mobile internet ad spending around the world nailed mobile spending in India at $\$ 173.2$ million in 2015 , set to double to $\$ 346.5$ million by the end of this year. That will amount to $29.5 \%$ of digital ad spending, or $4.9 \%$ of total media budgets.

Corresponding Author: -By Mrs. AnjalliVachhani.

Address: -Assistant Professor (Department of Accountancy) H.R. College of Commerce and Economics, University of Mumbai. 
By 2019, promoters in India will be spending much extra on mobile assignments - $\$ 1.32$ billion. That will account for a majority of all digital ad expenses (60.9\%), and $15.5 \%$ of total media advertising in India. Previous research has initiated that mobile marketers in India are focused on display and social ads, though their consideration is likely to swing in the upcoming years.

\section{Objectives of the study: -}

1. To study the theory of Mobile marketing in India.

2. To evaluate the effect of Mobile marketing on consumers' behavior in India.

\section{Methodology:-}

The study is qualitative and descriptive in nature and for the purpose of the present study; mainly secondary information have been used. The requisite data were collected from the e-journals on diverse websites, research papers, various reports and newspaper articles published online.

\section{Definition of 'Mobile Marketing':-}

Mobile marketing is marketing that occurs via mobile devices such as smart phones, tablets or PDAs. Mobile marketing makes usage of features of up-to-date mobile technology such as location services to modify marketing drives based on a consumer's place or regularly visited locations. Mobile marketing is a technique in which technology can endorse tailored goods or services to a consumer who is continuously associated to a link via their mobile device.

Mobile marketing may comprise promotions sent through SMS text messaging, MMS multimedia messaging, through downloaded apps using push notifications, through in-app or in-game marketing, through mobile web sites, or by using a mobile device to scan QR codes. Immediacy systems and location based services can make aware users based on geographic location or nearness to a service provider.

\section{Usage Of Mobile Marketing In India:-}

Figure 1:- Mobile Marketing Tactics Used by B2B Marketers Worldwide, May 2015 (\% of respondents)

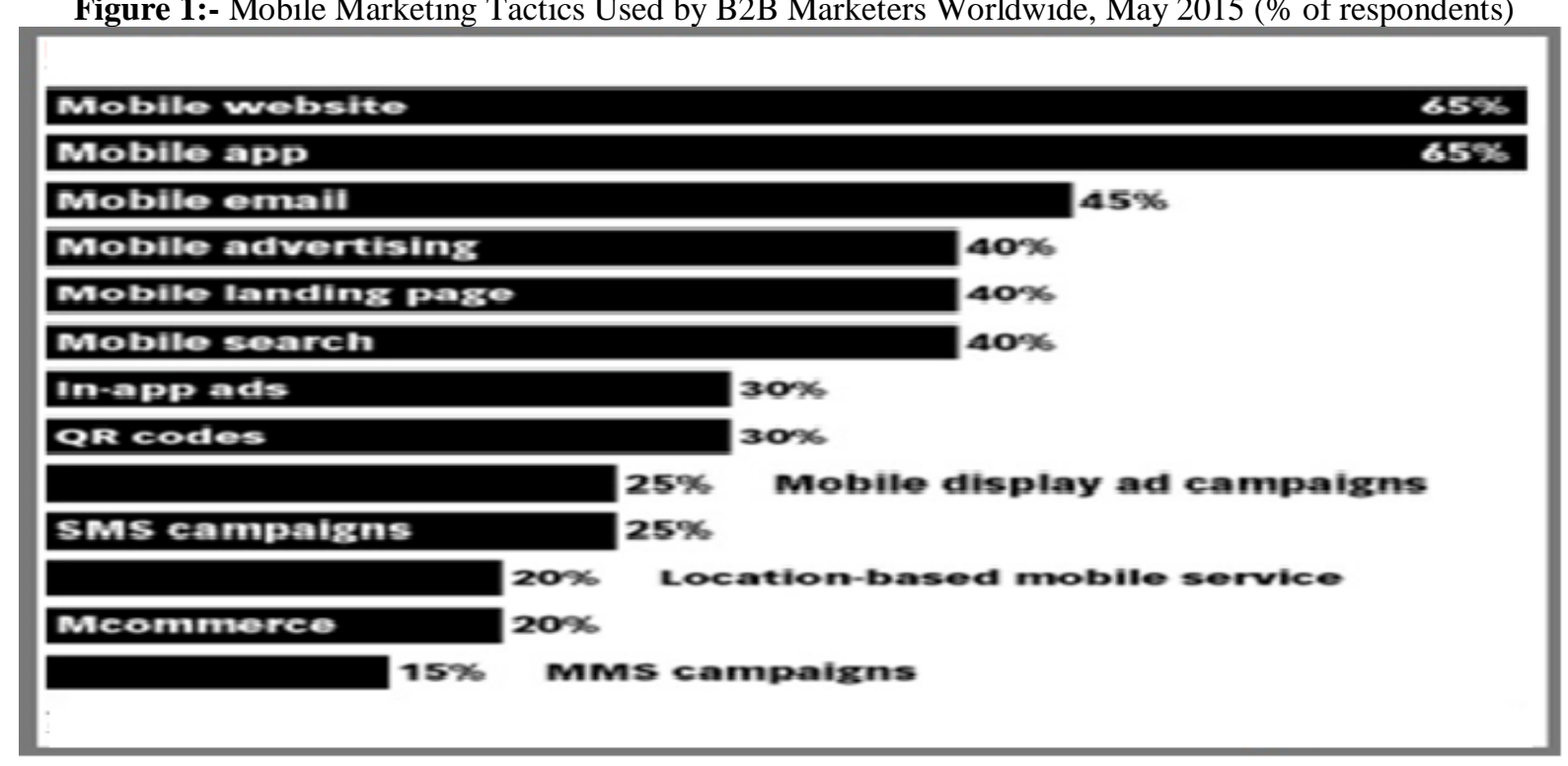

Source: Regalix, 'State of B2B Mobile Marketing 2015,' June 9, 2015 www.eMarketer.com 
Figure 2:- Attitudes toward Mobile Marketing among Digital Marketers in India, Sep 2015

(\% of respondents)

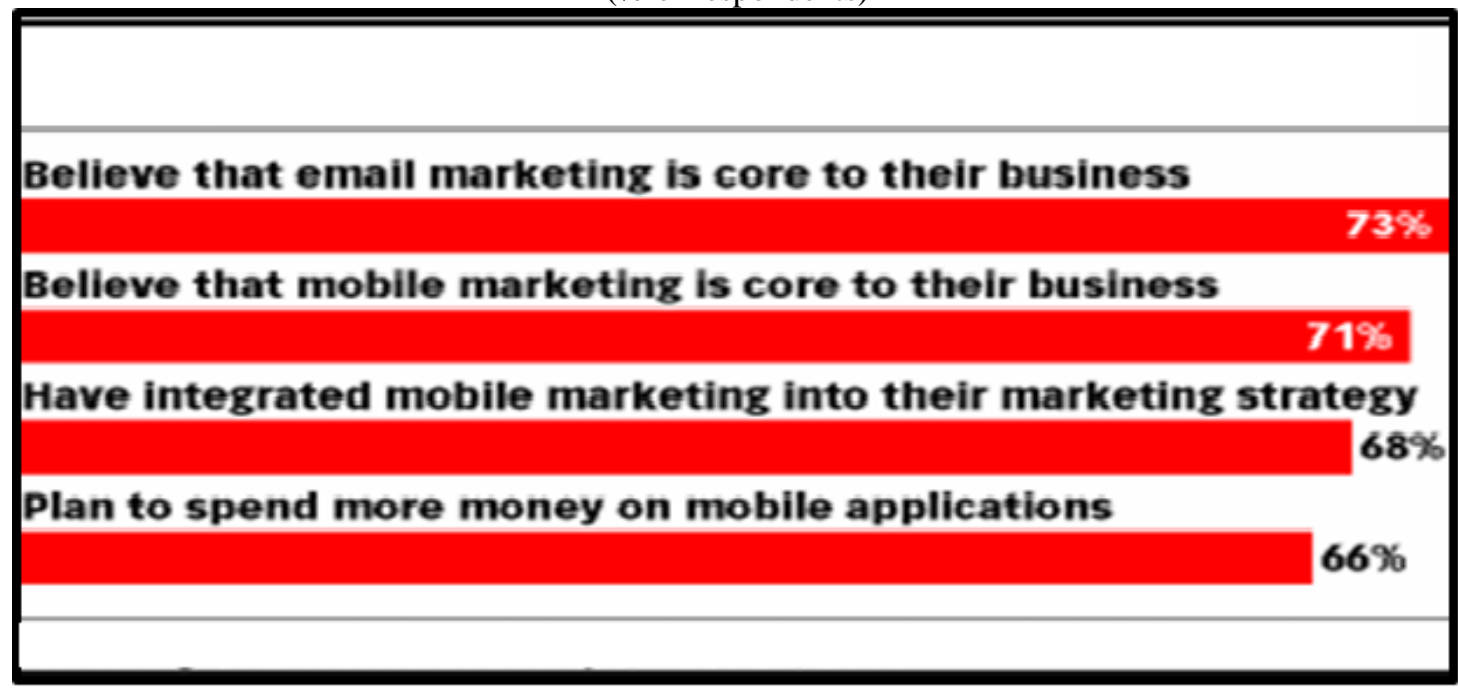

Source: EMart Solutions, 'Channel Loyalty Study 2015: Building and Nurturing Channel Relationships,' Oct 29, 2015

As seen in the figure 2 Research activists that dealers in India see mobile as a crucial portion of their marketing strength. According to EMart Solutions, $71 \%$ of digital marketers in India-including channel associates and brand managers - believe that mobile marketing is vital to their business. Nearly as many (68\%) said they have combined mobile into their total marketing plan.

Impact Of Mobile Marketing On Consumer Behaviour In India:-

Figure 3:- Effects of Mobile Marketing on Consumer Decision Making Process

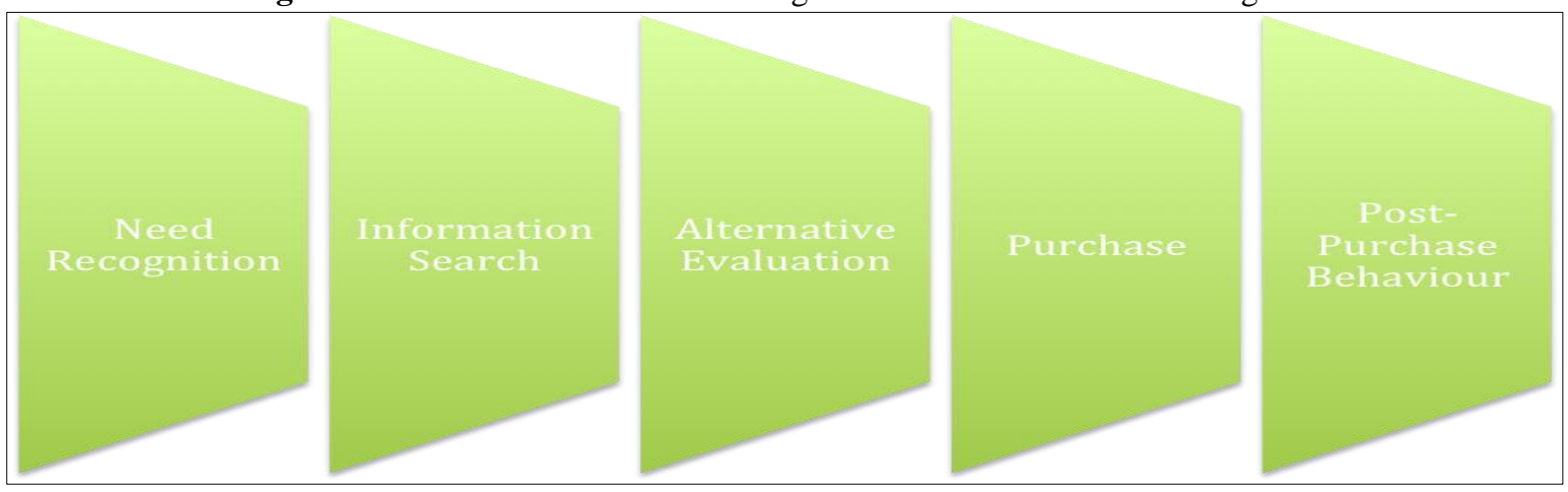

Source: http://erenkocyigit.com/effects-mobile-marketing-consumer-decision-making-process/

Effects of Mobile Marketing on Need Recognition Stage:-

The policymaking procedure for each customer starts when customers realize that they have a requirement for something. Need recognition happens when a customer is challenged with a variance between a real and wanted state. This is an energetic stage for marketers since marketers can build some of their operations in order to generate this disparity by seeking to make a need and make customers hunt out and purchase a product or service.

Marketers try to make an unevenness/customer need since they want to generate a want. How a want is formed? It is formed by marketing determinations that lead customers to identify that they have an unsatisfied need. Within these marketing determinations, thanks to mobile technology mobile marketing became one of the best significant tools for marketers.

Mobile technology permits dealers to attach with their consumers anywhere and anytime whether they are at work, in a store, or surfing the web. On the way to that; mobile technology also helps marketers to provide their 
offerings to their consumers by tailoring the offers based on the requirements of their consumers. Consequently, mobile marketing messages can act as exterior indications that help customers to identify a need, generating a decision-making course that might result in a buying.

In need recognition stage marketers' work is to locate their product or service as a key to a problem or a need that a customer may be facing.

For example, a push warning received on a mobile device for a forthcoming special day escorted by a list of optional gifts, and discount proposals can stimulate the recipient to jump into the purchasing process for a gift.

\section{Effects of Mobile Marketing on Information Search Stage:-}

After the customer has recognized a want or a need, the subsequent thing he or she will do is jerk an information search about different substitutes that he/she can purchase to satisfy his/her need. Information search can be completed internally or externally. An internal information search consists of exploiting information from memory, such as historical practices with the product and/or service. An external information search is a course of employing information from outside environment such as family and friends, public resources, radio, TV ads, digital and mobile ads.

Inside these channels, mobile marketing developed one of the most significant tools for marketers to effect on information search stage. Mobile technology provides the ease of retrieving and sharing information, that's why mobile marketing tools are very important to marketers.

\section{Effects of Mobile Marketing in Alternatives Stage:-}

After customers have recognized a want, they conduct a data research and then make a final conclusion set called induced set. At this point in order to create a final decision, they evaluate the substitutes. While giving a concluding decision customers take into consideration the diverse attributions of the product or service such as quality, price and location.

Like need recognition and information search stages at the alternative evaluation stage, mobile technology also varies from other modes. First of all, mobile devices and mobile services allow consumers to assess alternatives even when they are at physical stores. Mobile devices and mobile services can help customers enjoy the best of both physical and online worlds by merging the benefits of in-store and online shopping environments.

\section{Effects of Mobile Marketing on Purchase Stage:-}

After assessing alternatives, customers give a concluding decision and purchase product/service they choose. The purchase decision is already affected by previous decision-making course stages but still marketers have a chance to have effect on the customers who are previously at the purchase stage. Regarding this stage, marketers can make their products available to their customers and they can also be sure to make the purchase procedure calm and pleasurable for the customer.

At the purchase stage mobile technology plays significant role for marketers. For example mobile services can develop the customer shopping practice at the purchase stage by making the product ordering, buying and payment more appropriate. All of these developments may provide customers to protect time and money.

\section{Effects of Mobile Marketing on Post-Purchase Stage:-}

After a buyer makes a decision he/she assumes satisfaction to arise from his/ her decision. If the product /service do not encounter his/her requirements, then dissatisfaction might occur. At this point, the marketer may drop the chance to make this buyer a loyal user. That's why knowledgeable marketers make certain that their buyer is totally contented and does not cultivate any undesirable post-purchase feelings.

Similarly, mobile technology plays a vital role for marketers at the post - purchase stage. Mobile services can develop post-purchase consumer service experiences. For instance, customers can obtain updates on the order position for items purchased. Moreover, Consumer support can be improved by delivering more collaborating content (e.g., images, video), to customers irrespective of their place. 


\section{Conclusion:-}

It can be determined from the study that mobile phones now have a far superior dispersal in common man's life and can act as a very important instrument for the marketers and a stand for the mobile marketing communications. The marketers now a have a chance to influence fresher markets and consumer target sections, where it was really tough and affluent to carry on effective marketing activities. It is attaining much deeper in the Indian population where a $\mathrm{PC} /$ laptop has never stretched. Companies should emphasize extra on one to one marketing so as to target the right class of consumers, improving sales and producing brand consciousness. All efforts should be taken so as to comprise the consumer in a much superior way and for this the restrictive factors and obstacles are needed to be recognized and disconnected and diminished.

\section{References:-}

1. Emart Solutions, (2016, March 4), "Mobile Marketing Is Core to Businesses in India", Retrieved from http://www.emarketer.com/Article/Mobile-Marketing-Core-Businesses-India/1013662

2. ErenKocyigit, (2015, Dec 1), "The Effects of Mobile Marketing on Decision Making", Retrieved from https://www.proxbook.com/blog/the-effects-of-mobile-marketing-on-decision-making

3. ErenKocyigit, (2016), "Effects of Mobile Marketing on Consumer Decision Making

4. Process", Retrieved from http://erenkocyigit.com/effects-mobile-marketing-consumer- decision-makingprocess/

5. Venkatesh Shankar, Sridhar Balasubramanian (2009, May) "Mobile Marketing: A Synthesis and Prognosis", Retrieved from http://www.sciencedirect.com/science/article/pii/S1094996809000310

6. Netmera Mobile App, Engagement Program, (2015), "Effects of Mobile Marketing on Consumer Decision Making Process", Retrieved from http://www.slideshare.net/NetmeraMarketing/e-book-effects-of-mobilemarketing-on-consumer-decision-making-process

7. ErenKocyigit, (2016), "Effects of Mobile Marketing on Post-Purchase Stage", Retrieved from https://www.digitaldoughnut.com/articles/2016/january/effects-of-mobile-marketing-on-post-purchase-stage

8. "Marketing" Chapter 4, Retrieved from

9. https://quizlet.com/26488921/marketing-chapter-4-flash-cards/

10. "Consumer Decision Making" Chapter 5, Retrieved from

11. https://quizlet.com/32245510/chapter-5-consumer-decision-making-flash-cards/

12. "Mobile Marketing", (2017, Jan), Retrieved from http://www.parivartanfoundation.org/category/mobilemarketing/

13. "Mobile Marketing", Retrieved from http://www.investopedia.com/terms $/ \mathrm{m} / \mathrm{mobile-marketing.asp}$

14. "Digital Web Expert Services, Mobile Marketing", Retrieved from http://www.digitalwebexperts.com/

15. Hitesh Ramdasani\&B.B.Rayate, (Dec-Jan 2017), "Marketing through Mobile Phone: The next big thing in India", International Journal of Sales \& Marketing Management (IJSMM) Vol.6, Issue 1, Retrieved from http://www.academia.edu/31133825/MARKETING_THROUGH_MOBILE_PHONE_THE_NEXT_BIG_THI NG_IN_INDIA. 